adolescent overweight might have on the future prevalence of CHD in US adults.

The proportion of overweight adolescents (weight above the $95^{\text {th }}$ percentile for their age) who would become obese adults (BMI $\geq 30 \mathrm{~kg} / \mathrm{m}^{2}$ ) was estimated from US National Health and Nutrition Examination survey data. Current US data reveal that, at age 35 years, $25 \%$ of men and $32 \%$ of women are obese. The authors calculated that in 2020, 30-37\% of 35-year-old men and $34-44 \%$ of 35 -yearold women would be obese. The prevalence of $\mathrm{CHD}$ risk factors and the number of $\mathrm{CHD}$ events in young adults, a population normally considered at low risk for CHD, were predicted to rise as a consequence of this increase in obesity. The authors' model predicted that the prevalence of CHD would rise by $5-16 \%$ by 2035, which corresponds to more than 100,000 additional cases of CHD.

The authors point out that long-term projections must be interpreted with caution. For example, major changes in the treatment or prevention of obesity-related illness and CHD could change these estimates. They suggest, however, that such new treatments would need to be initiated in early adulthood to have a substantial effect on these projections.

Original article Bibbins-Domingo Ket al. (2007) Adolescent overweight and future adult coronary heart disease. $N$ Engl J Med 357: 2371-2379

\section{Low initial dose of aspirin is superior to a high dose after acute STEMI}

Immediate administration of aspirin after ST-segment-elevation myocardial infarction (STEMI) reduces the risk of vascular events, but the optimum dose in this setting is unknown. Berger et al. retrospectively analyzed data from two trials of fibrinolytic therapy in STEMI to determine the effect of high-dose versus lowdose aspirin on cardiovascular outcome and bleeding events.

From 1990 to 1997, the GUSTO I and GUSTO III trials enrolled patients with STEMI $<6 \mathrm{~h}$ after symptom onset. Patients were treated in the acute setting with a single dose of aspirin in the range 126-162 mg or 163-330 mg ('162 mg group' and ' $325 \mathrm{mg}$ group', respectively) at the discretion of the treating physician.
This analysis included a total of 48,422 patients, of whom $11,828(24.4 \%)$ were in the $325 \mathrm{mg}$ group and 36,594 (75.6\%) were in the $162 \mathrm{mg}$ group. After adjustment for baseline, treatment and procedural characteristics, there were no significant differences between the $325 \mathrm{mg}$ and the $162 \mathrm{mg}$ groups in the composite end point of mortality, myocardial infarction or stroke at $24 \mathrm{~h}$ (odds ratio [OR] 1.05, 95\% $\mathrm{Cl} 0.91-1.21$ ) or at 7 days (OR $1.00,95 \% \mathrm{Cl}$ $0.91-1.10)$, or in mortality at 30 days (OR 0.99 , $95 \% \mathrm{Cl} 0.87-1.12)$. The $325 \mathrm{mg}$ dose was independently associated with a significantly increased risk of in-hospital major or moderate bleeding compared with the $162 \mathrm{mg}$ dose (OR $1.14,95 \% \mathrm{Cl} 1.05-1.24 ; P<0.003)$.

The authors conclude that an initial aspirin dose of $162 \mathrm{mg}$ may be as effective as, and possibly safer than, a $325 \mathrm{mg}$ dose in patients with STEMI.

Original article Berger JS et al. (2008) Initial aspirin dose and outcome among ST-elevation myocardial infarction patients treated with fibrinolytic therapy. Circulation 117: 192-199

\section{Implantable device enables left atrial pressure monitoring in ambulatory patients with HF}

An increase in left atrial pressure (LAP) usually precedes symptom onset in patients with heart failure (HF). Accurate monitoring of LAP could, therefore, facilitate the early identification of incipient decompensation. In a recent paper, researchers have reported their initial experience with a new permanent implantable device that enables LAP to be monitored in ambulatory patients with HF.

Eight male patients with established HF underwent successful device implantation with no procedural complications. The mean device implantation time was $153 \mathrm{~min}$. Following implantation, all patients received at least $150 \mathrm{mg}$ aspirin daily and, for a minimum of 6 months, $75 \mathrm{mg}$ clopidogrel daily. Device-derived and catheter-derived left atrial waveforms showed excellent concordance at baseline. At right heart catheterization 3 months later, $87 \%$ of device-derived LAP measurements were within $5 \mathrm{mmHg}$ of pulmonary capillary wedge pressure measurements, and $96 \%$ were within $10 \mathrm{mmHg}$. The mean net device 